\title{
Conduction Failures in Rabbit Saphenous Nerve Unmyelinated Fibers
}

\author{
Zhi-Ru Zhu ${ }^{a, c}$ Xiao-Wei Tang ${ }^{b}$ Wen-Ting Wang ${ }^{c}$ Wei Ren ${ }^{d}$ Jun-Ling Xing ${ }^{c}$ \\ Jun-Ran Zhang ${ }^{c}$ Jian-Hong Duan ${ }^{c}$ Yu-Ying Wang ${ }^{c}$ Xiying Jiao ${ }^{c}$ San-Jue Huc \\ ${ }^{a}$ Department of Biomedical Engineering and ${ }^{b}$ College of Science, Zhejiang University, Hangzhou, \\ CInstitute of Neuroscience, Fourth Military Medical University, and ${ }^{\mathrm{d} C}$ College of Life Sciences, Shaanxi Normal \\ University, Xi'an, China
}

\section{Key Words}

Fibers, unmyelinated $\cdot$ Conduction velocity slowing .

Conduction failure $\cdot 4$-Aminopyridine $\cdot$ ZD7288

\begin{abstract}
Recent experimental and theoretical data indicate that the functional capabilities of axons with specialized structures are much more diverse than traditionally thought. However, few observations were concerned with the main axons without arborization. In the present study, electrical stimulation of the saphenous nerve at different frequencies $(2,5,10,20$ $\mathrm{Hz}$ ) was used to test the role of activity-dependent effects on the pattern of action potentials that propagate along individual unmyelinated fibers ( $C$ fibers) within the trunk of the saphenous nerve in rabbits. Three basic types of $C$ fiber responses to repetitive stimulation were observed: type-1 fibers showed an entrained response without conduction failure; type-2 fibers discharged with intermittent conduction failures; while only sporadic conduction failures happened in type 3 . The failure modality in type-2 and type-3 fibers is closely related to the conductive distance as well as the frequency and duration of stimuli which lead to a critical level of conduction velocity slowing. A novel fluctuation in interspike intervals was always observed immediately be-
\end{abstract}

fore the occurrence of the failures, implying that the fluctuation of conduction velocity is correlated with imminent failures. Both the 4-aminopyridine-sensitive potassium current and hyperpolarization-activated cation current were recognized to be involved in the regulation of conduction failure patterns. The results confirmed, at least in part, the existence of conduction failures in the main axon of $C$ fibers, suggesting that axonal operations may also be determinants for adaptation phenomenon and information processing in peripheral nervous system.

Copyright $\odot 2009$ S. Karger AG, Basel

\section{Introduction}

It is commonly agreed that different regions of the neuron perform specific signaling tasks. The pattern of firing is determined in a number of special regions responsible for signal integration, such as receptors, axon hillock and synapse. In contrast, the axon is usually believed to be specialized for carrying signals faithfully over long distances and to work as a relatively simple relay line $[1,2]$. Recently, some experimental and theoretical data suggest that the functional capabilities of axons are much more diverse than traditionally thought. In other

\section{KARGER \\ Fax +41613061234 \\ E-Mail karger@karger.ch}

www.karger.com
(C) 2009 S. Karger AG, Basel

1424-862X/09/0173-0181\$26.00/0

Accessible online at:

www.karger.com/nsg
San-Jue Hu

Institute of Neuroscience, Fourth Military Medical University

17 West Chang-le Road

Xi'an, Shaanxi 710033 (China)

Tel. +86298477 4590, Fax +86298324 6270, E-Mail sjhu@fmmu.edu.cn 
words, the function of the axon is no longer limited to the conduction of the action potential, but is also involved in the regulation of patterns of firing [3-7]. For example, conduction failure which is considered one of the crucial operations for processing the firing pattern has often been observed in the terminal of axons with specialized structures such as branch points, axonal swelling or bottleneck (that is, an axon entering the soma) $[3,6,8-13]$ suggesting that the complex changes in firing pattern are determined by an intrinsic activity-dependent effect of conduction velocity $(\mathrm{CV})$ together with the intrinsic geometrical properties of the axon $[6,14]$. Axon terminals and the zone entering the soma are structures with nonuniform diameters, while the main axon, located in the trunk of the peripheral nerve, is a structure with uniform diameters $[8,15]$. This raises the interesting question of whether conduction failures can occur in the main axons with uniform diameter structures.

It is well known that the $\mathrm{CV}$ of nerve impulse propagation is affected by previous impulse activity in the unmyelinated fibers (C fibers) of mammalians [16-18] and humans $[14,19,20]$, which is also termed the activity-dependent effect of slowing or speeding [19]. In previous work at our laboratory, the activity-dependent effect on $\mathrm{CV}$ was observed to be influenced by the frequency and the time course of repeated stimulation as well as the period between condition and test impulses [21]. Shim et al. [22] recently reported that concurrent speeding and slowing of conduction can be observed in the same $\mathrm{C}$ fiber in response to a train of twin-pulse stimuli. These results suggest that the activity-dependent effect on CV possesses non-linear characters which might result in complex firing behavior. So, it is reasonable to postulate that, in some main axons with uniform diameter structures, the nonlinear property of activity-dependent effects on $\mathrm{CV}$ might cause conduction failure and therefore result in significant changes in the firing pattern. Such effects, if demonstrated to be true, may contribute to signal processing in some $\mathrm{C}$ fibers.

To test the hypothesis that some $\mathrm{C}$ fibers with uniform diameter structure can exhibit conduction failure, the present study investigated the changes in firing patterns in response to stimulus trains applied to $\mathrm{C}$ fibers within the nerve trunk. Three $\mathrm{C}$ fiber types were distinguished according to the characteristics of conduction failures. The occurrence of conduction failure was found to be closely related to the degree of CV slowing and the fluctuations in the amplitude of interspike intervals (ISIs). Both the 4-aminopyridine (4-AP)-sensitive potassium current $\left(\mathrm{I}_{4-\mathrm{AP}}\right)$ and hyperpolarization-activated cation current $\left(\mathrm{I}_{\mathrm{h}}\right)$ were demonstrated to be involved in the changes of the firing series patterns. The results confirmed, at least in part, the existence of conduction failures in the main axon of $\mathrm{C}$ fibers where there are no effects of obvious geometrical factors.

\section{Materials and Methods}

\section{Animals and Surgery}

Adult rabbits of both sexes, weighing between 1.8 and $2.2 \mathrm{~kg}$, were used under a research protocol approved by the Fourth Military Medical University. Anesthesia was induced with sodium pentobarbital (40 mg/kg i.v.). The trachea was cannulated and the body temperature was maintained near $37^{\circ} \mathrm{C}$ using a heating blanket controlled by a rectal thermometer probe. As shown in figure $1 \mathrm{~A}$, the saphenous nerve of one hind leg was carefully exposed at three sites where skin pools were prepared. One site was used for electrical stimulation, one site for single fiber recording, and another site was used for drug administration or occasional electrical stimulation of the nerve.

\section{In vivo Electrophysiological Recording of Single C Fiber}

Discharges

In the proximal stimulation pool, the trunk of the saphenous nerve was cut proximally. A pair of platinum stimulating electrodes was placed under the nerve trunk at the distal end and covered with warm (about $37^{\circ} \mathrm{C}$ ) mineral oil. In the middle drug application pool, the nerve trunk was separated about $4-5 \mathrm{~cm}$ and covered with a warm physiological saline solution with or without drug. When a second stimulus was needed, a pair of platinum electrodes was placed under the nerve trunk at this intermediate site between the proximal stimulus site and the recording site and also covered with warm mineral oil.

A pair of fine platinum thread electrodes ( $30 \mu \mathrm{m}$ in diameter) was used as recording electrodes in the recording pool. With the help of a microscope, a fine filament of nerve fibers was dissected and the proximal end was placed on the recording electrode. The detected discharges were amplified (VC-11, Nihon Kohden, Japan) and transferred to a computer via an $\mathrm{A} / \mathrm{D}$ board with a signal sample rate of 10 or $100 \mathrm{kHz}$. The $\mathrm{CV}$ of a fiber was determined by dividing the distance between the stimulating and recording electrodes by the action potential latency. Fibers with a CV of $<2 \mathrm{~m} / \mathrm{s}$ were classified as $\mathrm{C}$ fibers $[23,24]$. If the amplitude and shape of the action potentials remained the same during the recordings, they were defined as responses from a single $\mathrm{C}$ fiber; sometimes collision tests were also used (see below) [24]. Only these single $\mathrm{C}$ fibers were studied further.

\section{Electrical Stimulation}

It is known that a repetitive electrical stimulus can induce blockade of impulse propagation in the region under the anode electrode through anode blockade, and that A fibers can be blocked at a weaker intensity of stimulus than C fibers [25-27]. In the present study, in order to avoid anodal blockade, the anode electrode was arranged at the further position from the recording site. The intensity of the stimulus was maintained below the blocking intensity of A fibers. 
Fig. 1. Schematic drawing of experimental setup. A Electrical stimuli were applied to the saphenous nerve of the rabbit hind limb in vivo. The nerve was kept in continuity, allowing activation of fibers by adequate stimulation. The nerve trunk was stimulated at either $S_{1}$ or $S_{2}$ (when collision experiment was performed), and the antidromically propagating action potentials in a single $C$ fiber were recorded at $\mathrm{R}$. The pool at $\mathrm{S}_{2}$ was also used to apply chemicals. $\mathrm{S}, \mathrm{D}, \mathrm{R}$ and $\mathrm{E}$ indicate the stimulation pool, drug pool, recording pool and ground, respectively. B Stimulation protocol: the interstimulus intervals for the repetitive stimulus were $500,200,100$ or $50 \mathrm{~ms}$ (i.e., $2,5,10$ or $20 \mathrm{~Hz}$ ) for a total of $400,500,800$ or 1,000 pulses, corresponding stimulus train durations of 200,100, 80 and $50 \mathrm{~s}$, respectively. There is a 10 -min rest between two trains of repetitive stimulation.

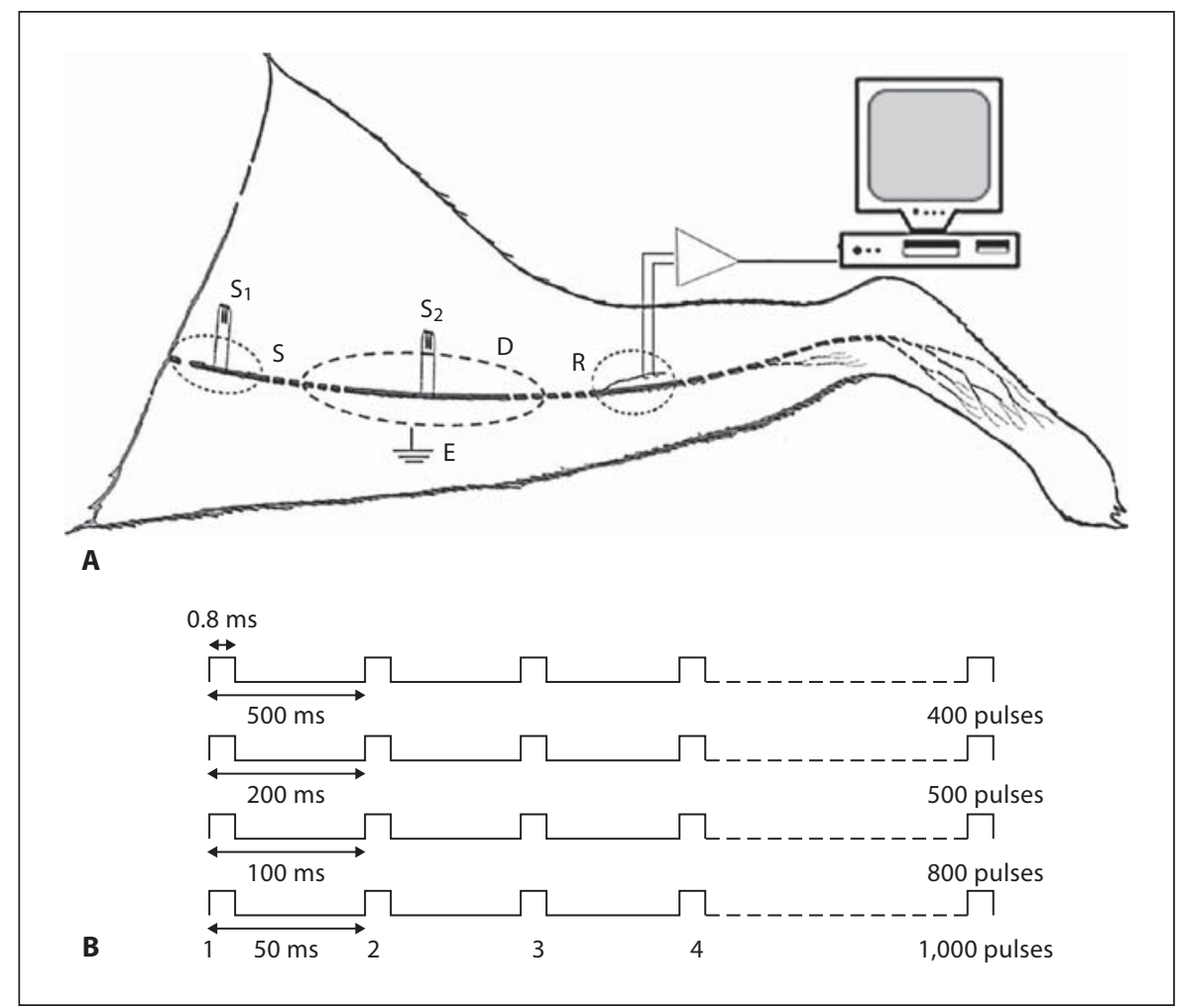

After a single $\mathrm{C}$ fiber had been identified, the whole nerve trunk was stimulated electrically (pulse width $0.8 \mathrm{~ms}$ ). In most experiments, a standard repetitive stimulation series with intensity $50 \%$ above the threshold was applied and the repetitive pulses given were $2 \mathrm{~Hz}$ for $200 \mathrm{~s}, 5 \mathrm{~Hz}$ for $100 \mathrm{~s}, 10 \mathrm{~Hz}$ for $80 \mathrm{~s}$ and 20 $\mathrm{Hz}$ for $50 \mathrm{~s}$ (fig. 1B). The stimulation of other frequencies and durations were also selectively used according to the requirement of specific experiments. The interval between two stimulation series was at least $10 \mathrm{~min}$ to allow recovery from the effects of each stimulus train.

The initial $\mathrm{CV}\left(\mathrm{CV}_{\mathrm{i}}\right)$ was calculated from the latency of the first action potential after resting for more than $10 \mathrm{~min}$. This latency was compared with the latency of each action potential responding to repetitive stimulus pulses at different rates, and the difference as a percentage of $\mathrm{CV}_{\mathrm{i}}$ was termed 'CV slowing'. $\mathrm{CV}$ slowing represents the cumulative long-lasting hyperpolarization and therefore reflects neural accommodation [19].

Confirming the Same Single Unit Recording by Collision Test

In a group of experiments, the nerve trunk was stimulated at two different sites to study the effects of different conduction distances on firing pattern changes. In this case, a collision test [28, 29] was made before the experimental procedure to confirm that the recorded firing evoked by stimulations at two different sites was of the same $C$ fiber. The stimulation electrodes, $S_{1}$ and $S_{2}$, are shown in figure $1 \mathrm{~A}$. The latency of the discharge induced by $S_{1}$ was longer than that induced by $S_{2}$ as the distance from $S_{1}$ to the recording site was further than that of $S_{2}$. When the nerve trunk was synchronously stimulated using both $\mathrm{S}_{1}$ and $\mathrm{S}_{2}$ and the recording was of the same single $\mathrm{C}$ fiber, the antidromic discharges from $\mathrm{S}_{1}$ collided with orthodromic discharges from $S_{2}$ at an intermediate site between $S_{1}$ and $S_{2}$. Therefore, only the antidromic discharge with the shorter latency from $S_{2}$ was recorded. The waveforms elicited by two different stimulation electrodes were also used as criteria for the identification of the same single $\mathrm{C}$ fiber.

\section{Chemicals}

A blocker of hyperpolarization-activated cation current $\left(\mathrm{I}_{\mathrm{h}}\right)$, ZD7288 (Tocris Cookson, UK), and an antagonist of sustained 4AP-sensitive outward current $\left(\mathrm{I}_{4-\mathrm{AP}}\right)$, (Sigma) were dissolved and diluted to the desired concentrations with $0.9 \%$ saline solution, and applied into the drug administration pool, respectively (fig. 1A).

\section{Statistical Analysis}

Data are expressed as means \pm SEM. Data were analyzed using paired or unpaired Student's t test as appropriate. $p$ values of $<0.05$ are considered statistically significant.

\section{Results}

\section{Classification of C Fibers}

The $\mathrm{C}$ fibers were classified into three types based on their different patterns of conduction failure in response to the repetitive stimulation of the nerve trunk (fig. 2). In 
Fig. 2. Examples of firing pattern of three types of C fibers. A Non-failure type $1 \mathrm{C}$ fiber. A train of action potentials induced by repetitive stimulation at $20 \mathrm{~Hz}$, no conduction failure was observed. B Intermittent failure type $2 \mathrm{C}$ fiber. Trains of action potentials were induced by repetitive stimuli at 2, 5, 10 and $20 \mathrm{~Hz}$ (from top to bottom). C Sporadic failure type $3 \mathrm{C}$ fiber. Firing series induced by repetitive stimuli at 2, 5, 10 and $20 \mathrm{~Hz}$ were recorded, sporadic failures were found within the series.

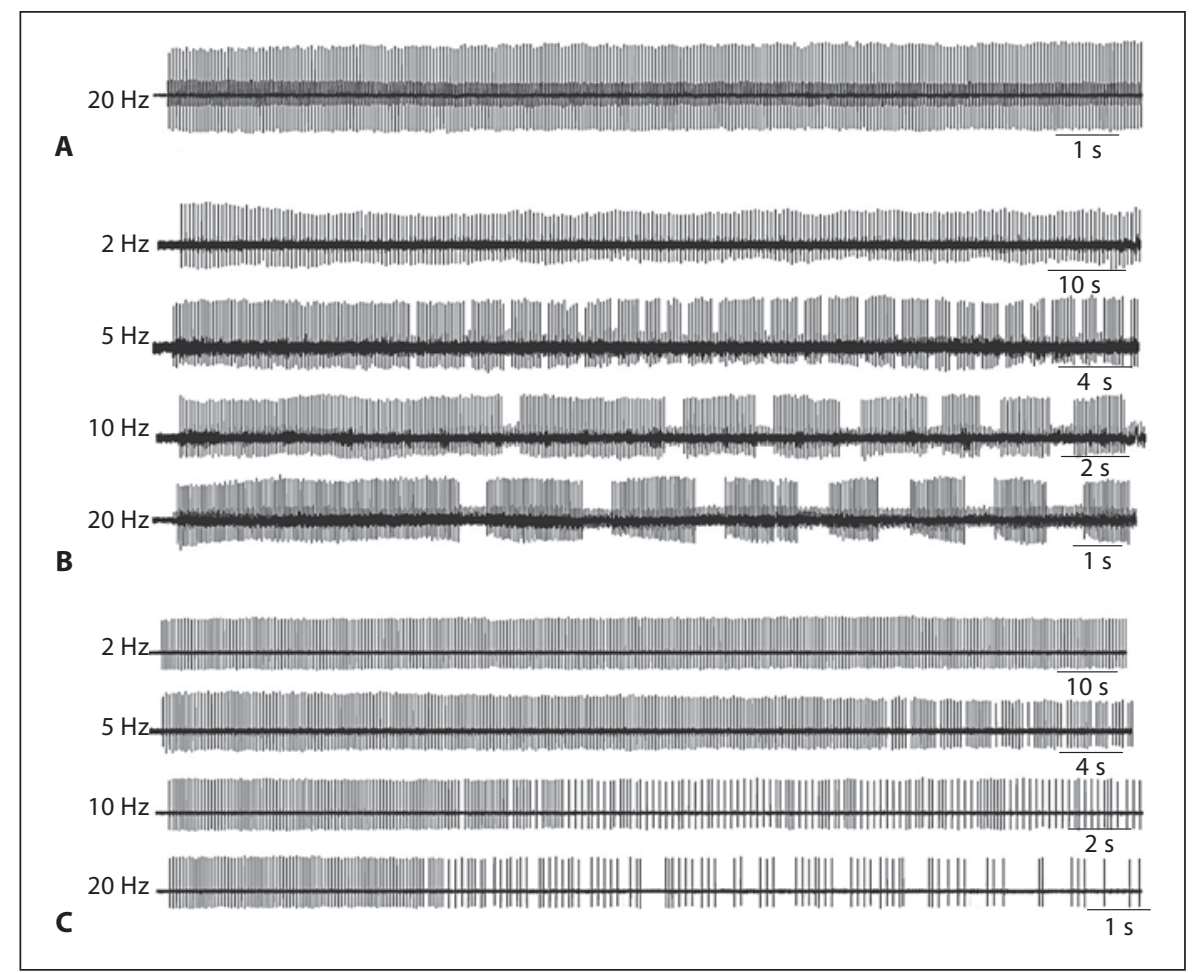

response to the $20-\mathrm{Hz}$ stimulation for $50 \mathrm{~s}$, type- 1 fibers fired continuously and no failure happened; we termed these non-failure $\mathrm{C}$ fibers. A typical example is shown in figure 2A. Type-2 fibers exhibited intermittent failures. When the nerve trunk was given repetitive stimulations of $2,5,10$ and $20 \mathrm{~Hz}$, the conduction failures appeared intermittently. As shown in figure $2 \mathrm{~B}$, there was no conduction failure under the $2-\mathrm{Hz}$ stimulation. When the stimulation frequency was increased from 5 , to 10 , to 20 $\mathrm{Hz}$, conduction failure occurred and gradually increased. Type-3 fibers exhibited sporadic conduction failure (fig. 2C). During repeated 2-Hz stimulation, there was no conduction failure. As the stimulation rate was increased from 5 to $20 \mathrm{~Hz}$, conduction failure occurred sporadically and developed significantly with the increase in stimulation frequency.

In the present study, a total of $510 \mathrm{C}$ fibers were tested. Eighty-six (17\%) were classified as non-failure type-1 C fibers and had a $\mathrm{CV}_{\mathrm{i}}$ of $1.41 \pm 0.11 \mathrm{~m} / \mathrm{s}$ (mean $\pm \mathrm{SEM}$ ). Seventy-five (15\%) were classified as intermittent failure type- $2 \mathrm{C}$ fibers and had a $\mathrm{CV}_{\mathrm{i}}$ of $0.84 \pm 0.12 \mathrm{~m} / \mathrm{s}$. The other 349 fibers (68\%) were classified as sporadic failure type- $3 \mathrm{C}$ fibers and had $\mathrm{CV}_{\mathrm{i}}$ of $1.01 \pm 0.18 \mathrm{~m} / \mathrm{s}$. There were significant differences between the $\mathrm{CV}_{\mathrm{i}}$ of the three types of fibers $(p<0.05$, unpaired $t$ test). The threshold of electrical stimulation with a 0.8 -ms pulse width ranged from 0.22 to $4.4 \mathrm{~mA}$, and no obvious differences were observed on the threshold among the three types of $\mathrm{C}$ fibers.

\section{Relationship between Interspike Intervals and CV in} the Three Types of $C$ Fibers

Figure $3 \mathrm{~A}$ shows the relationship between ISIs and CV of a typical non-failure $\mathrm{C}$ fiber; the conduction distance between the stimulus and recording electrodes was 100 $\mathrm{mm}$. During the stimulation period of $20 \mathrm{~Hz}$ for $50 \mathrm{~s}$, the ISI values closely coincided with the inter-stimulus interval (50 ms), and no conduction failure occurred. During the same experiment, the CV decreased from 1.38 to 1.24 $\mathrm{m} / \mathrm{s}$, and the decline in CV could be described as an exponential drop, indicating that progressive activity-dependent slowing continues throughout the stimulus. However, at the beginning of the repetitive stimulus the ISI was shorter than inter-stimulus interval and CV increased temporarily (i.e., transient speeding of conduction occurred).

Figure $3 \mathrm{~B}$ shows a representative example of the intermittent failure $\mathrm{C}$ fibers. The conduction distance between the stimulus and recording electrode was $100 \mathrm{~mm}$, and stimulation was also delivered at $20 \mathrm{~Hz}$ for $50 \mathrm{~s}$. Conduc- 


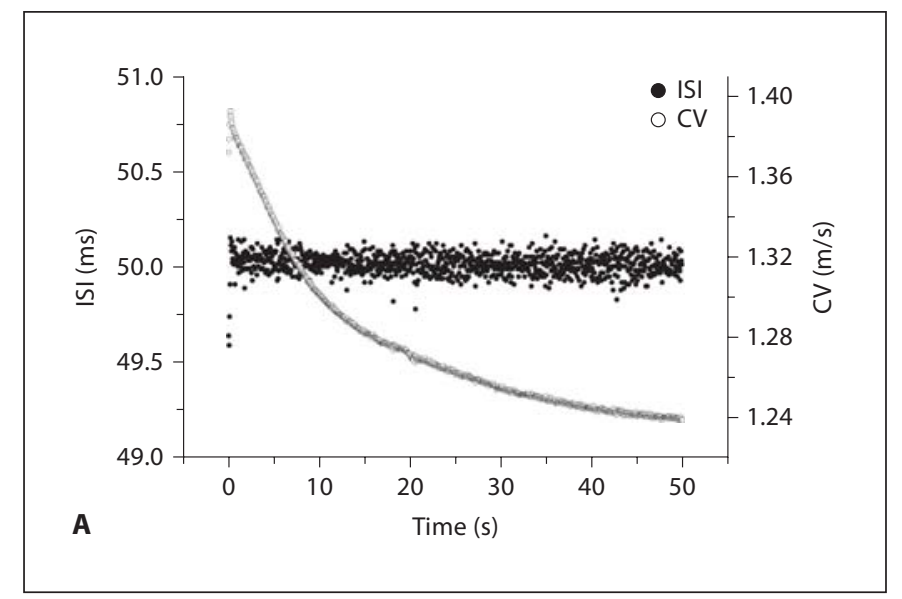

Fig. 3. Example showing the relationship of the interspike interval (ISI) series and conduction velocity (CV) of three types of C fibers. The whole stimulation is $20 \mathrm{~Hz}$ for $50 \mathrm{~s}$. ISI was calculated as the value (ms) of spike intervals and aligned in series along with the time. The CV was valued as the distance between the recording and stimulating electrode divided by the time used to produce a corresponding spike (latency period), though in some way it reflects the cumulative value $(\mathrm{m} / \mathrm{s})$ of previous action potentials on $\mathrm{CV}$ and collated to the non-failure $\mathrm{C}$ fiber $(\mathbf{A})$, intermittent failure C fiber (B), and sporadic failure (C). For the purpose of showing the details of the ISI series, the vertical axes are displayed at different scales in the different figures.

tion failure occurred when the CV dropped from 0.846 to $0.747 \mathrm{~m} / \mathrm{s}$. After a short period of firing blockade, the firing train recovered spontaneously with a rise in $\mathrm{CV}$ (from 0.747 to $0.777 \mathrm{~m} / \mathrm{s}$ ). Then, CV became slower and slower until failure occurred again.

In figure 3C, a typical example of the sporadic failure $\mathrm{C}$ fibers is displayed. The conduction distance was $95 \mathrm{~mm}$ and stimulation was delivered at $20 \mathrm{~Hz}$ for $50 \mathrm{~s}$. Following repetitive stimulation, the CV dropped from 1.059 to $0.882 \mathrm{~m} / \mathrm{s}$, failure then occurred sporadically. The decline in CV before failure could also be described as an exponential drop, but was followed by slight fluctuation around a new slower $\mathrm{CV}$.

Figure $4 \mathrm{~A}$ shows the relationship between the extent of activity-dependent $\mathrm{CV}$ slowing after stimulation for $25 \mathrm{~s}$ at $20 \mathrm{~Hz}$ and the $\mathrm{C}$ fibers' $\mathrm{CV}_{\mathrm{i}}$. The three types of $\mathrm{C}$ fibers formed separate clusters. The cluster of the sporadic failure $C$ fibers (with a $\mathrm{CV}_{\mathrm{i}}$ of $1.00 \pm 0.17 \mathrm{~m} / \mathrm{s}$ ) showed an activity-dependent CV slowing of $38 \pm 12 \%$.
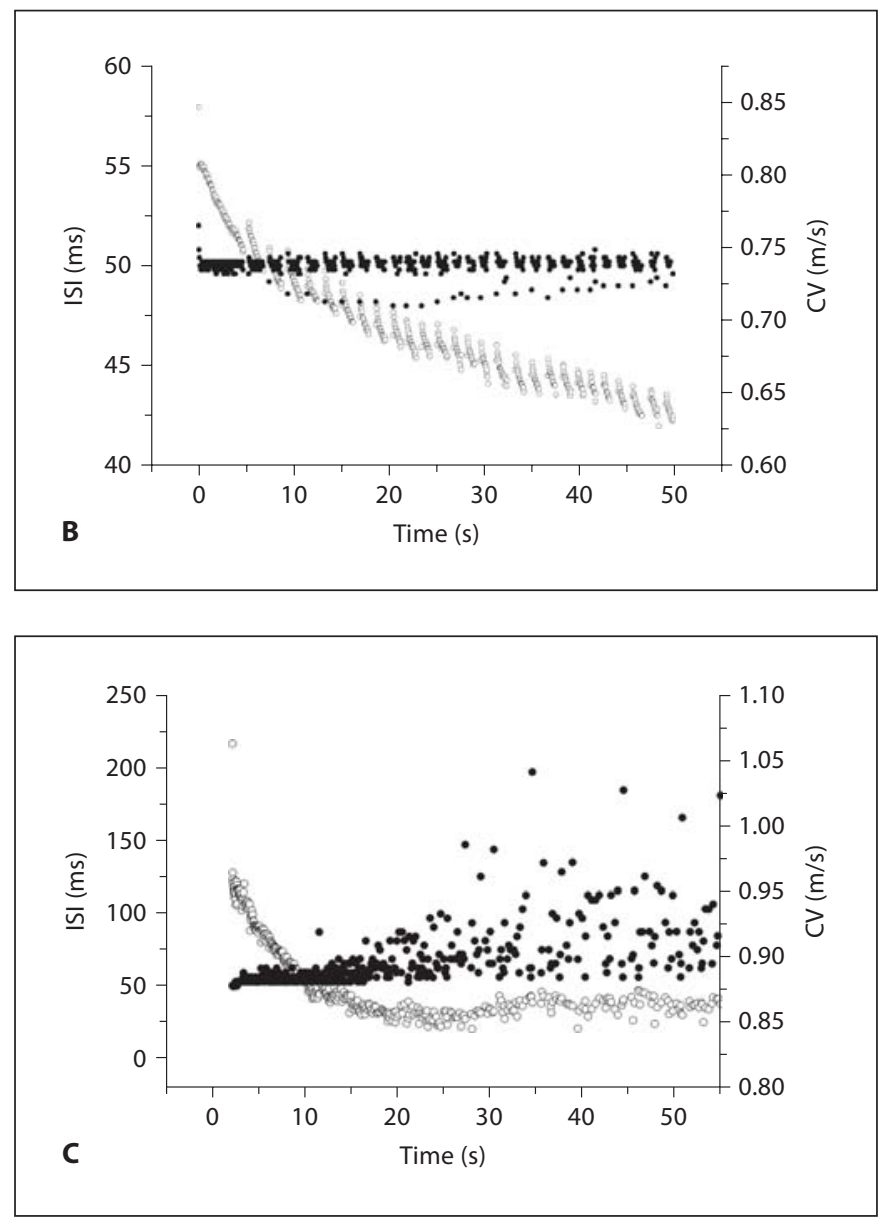

While the cluster of the intermittent failure $\mathrm{C}$ fibers (with a $\mathrm{CV}_{\mathrm{i}}$ of $0.83 \pm 0.11 \mathrm{~m} / \mathrm{s}$ ) and the non-failure $\mathrm{C}$ fibers (with a $\mathrm{CV}_{\mathrm{i}}$ of $1.40 \pm 0.11 \mathrm{~m} / \mathrm{s}$ ) displayed a mean activitydependent CV slowing of $14.3 \pm 4.4$ and $12.2 \pm 4.9 \%$, respectively. So, the cluster of the sporadic failure $\mathrm{C}$ fibers showed much greater activity-dependent $\mathrm{CV}$ slowing than the other two types of units. Among the sporadic failure $\mathrm{C}$ fibers there was a negative correlation between activity-dependent $C V$ slowing and $\mathrm{CV}_{\mathrm{i}}(\mathrm{n}=60, \mathrm{r}=-0.4$, $\mathrm{p}<0.01$ ). Such a tendency was evident among the other two types of units for intermittent failure C fibers $(n=29$, $\mathrm{r}=-0.39, \mathrm{p}<0.05)$ and non-failure firing $\mathrm{C}$ fibers $(\mathrm{n}=$ $28, r=-0.42, p<0.05)$. This tendency may be consistent with the idea that larger axons have a lower surface to volume ratio, and thus proportionally less accumulation of ions occur in larger axons compared to the smaller axons.

Figure $4 \mathrm{~B}$ illustrates that within the three types, the sporadic failure $\mathrm{C}$ fibers showed the greatest degree of 


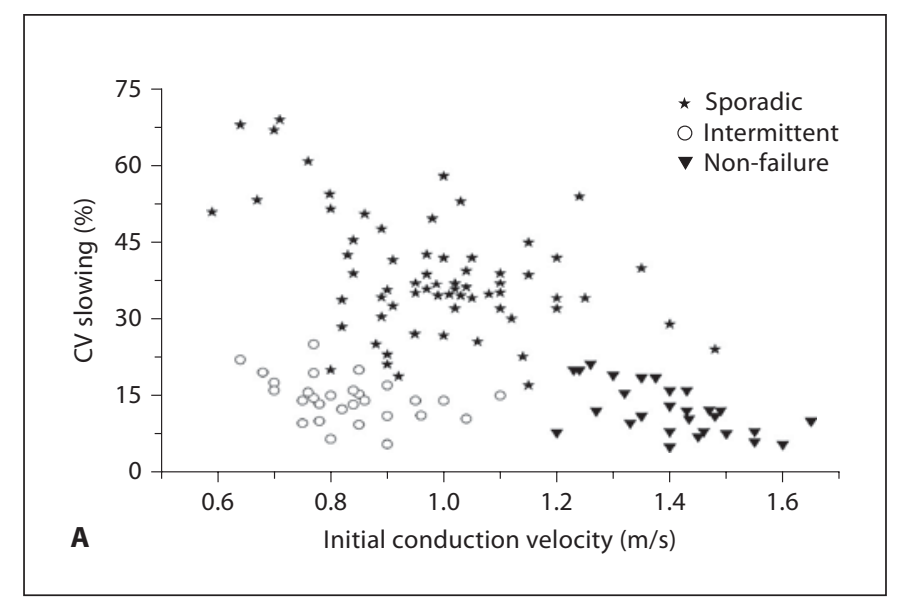

Fig. 4. Correlation between $\mathrm{CV}$ slowing and three types of $\mathrm{C}$ fibers. A Relationship between $\mathrm{CV}_{\mathrm{i}}$ and the degree of $\mathrm{CV}$ slowing after stimulation of $20 \mathrm{~Hz}$ for $25 \mathrm{~s}$. Three types of $\mathrm{C}$ fibers formed three separated clusters: $\boldsymbol{\nabla}=$ the 28 non-failure firing $\mathrm{C}$ fibers; $O=$ the 29 intermittent failure firing $C$ fibers; $\star=$ the 60 sporadic failure firing $C$ fibers. $\mathbf{B}$ Effect of stimulation frequency (each stimulus consists of 500 pulses) on CV slowing in three

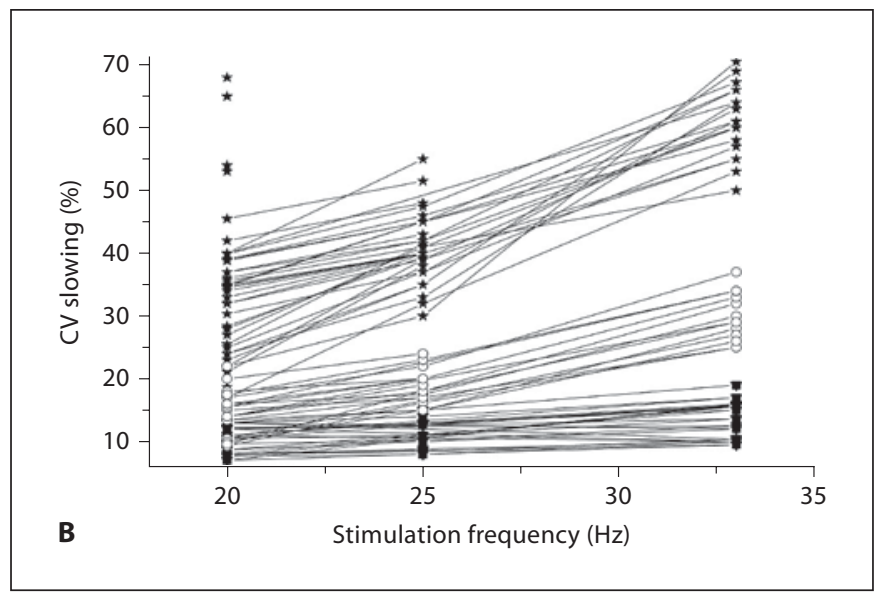

types of C fibers. Degree of CV slowing after repetitive stimulation are illustrated in 50 sporadic failure firing $C$ fibers, 16 intermittent $\mathrm{C}$ fibers and 14 non-failure $\mathrm{C}$ fibers. Some intermittent failure $\mathrm{C}$ fibers and sporadic failure $\mathrm{C}$ fibers fail at 25 or $33 \mathrm{~Hz}$, so the numbers of the sample at 25 and $30 \mathrm{~Hz}$ were less than that at $20 \mathrm{~Hz}$.

around the inter-stimulus interval and the amplitude of the fluctuation (positive peak to negative peak) is less than $0.2 \mathrm{~ms}$. Then comes phase 3 where the amplitude of ISI fluctuation increased gradually up to a maximal value (about 1.5-3.0 ms) when failure occurred. The maximal amplitude of ISI fluctuation in the intermittent failure $\mathrm{C}$ fibers was significantly bigger than that of sporadic fail-

Therefore, the samples of both the sporadic failure $\mathrm{C}$. bers and the intermittent failure $\mathrm{C}$ fibers decreased with the increase in stimulation frequency as they both displayed failures. The differences in the degree of CV slowing between the three types of $\mathrm{C}$ fibers suggest the segregation of the $\mathrm{C}$ fibers into three distinct groups.

\section{Phases in Variance of ISI Series before Conduction Failure}

Next, we investigated the temporal variation of ISI before conduction failure. The ISI time course of an intermittent failure $\mathrm{C}$ fiber and a sporadic failure $\mathrm{C}$ fiber are shown in figure $5 \mathrm{~A} 1$ and $5 \mathrm{~B} 1$, respectively. The ISIs preceding conduction failure could be divided into three phases according to characteristics of the variance or fluctuation of ISI in both types of units. In the scatter plots (fig. 5A2, B2) we can see that the amplitude of ISI variance becomes greater than that of the inter-stimulation interval $(50 \mathrm{~ms})$ at the very beginning of repetitive stimulation, which is defined as phase 1 . Phase 2 comes after phase 1, in which the ISI displays small fluctuation
Fig. 5. Comparison of ISI series among three types of $C$ fibers. A1 The ISI series of an intermittent failure $C$ fiber, each point represents a spike. A2 The segment in the frame of $\mathbf{A} \mathbf{1}$ is shown with a larger time scale to illustrate the course before failure. B1 The ISI series of a sporadic failure C fiber. B2 Segment in the frame of B1 is shown with a larger time scale to illustrate the course before failure. Three phases are defined as: phase-1 (P1) = the initial period of ISI series, the $\Delta$ ISI (difference between ISI and inter-stimulation interval) keeps decreasing in this period; phase-2 (P2) = the ISI fluctuation is smaller than $0.2 \mathrm{~ms}$ and ISI is roughly equal to the inter-stimulation interval; phase-3 (P3) = the amplitude of ISI fluctuation is greater than $0.2 \mathrm{~ms}$ and increases gradually. C The ISI series of a non-failure firing $\mathrm{C}$ fiber in which only P1 and $\mathrm{P} 2$ are exhibited. D The histogram represents the maximal $\Delta$ ISI of $\mathrm{P} 1$ in three types of $\mathrm{C}$ fibers $(\mathrm{p}<0.01$, unpaired t test; nonfailure $\mathrm{n}=28$; intermittent $\mathrm{n}=29$; sporadic $\mathrm{n}=60$ ). $\mathrm{E}$ Duration of $\mathrm{P} 3$ at different stimulation frequencies $(\mathrm{p}<0.05$, unpaired $\mathrm{t}$ test; intermittent $\mathrm{n}=29$; sporadic $\mathrm{n}=60$ ). $\mathbf{F}$ Maximal amplitude of ISI fluctuation before failure at different stimulation frequencies $(\mathrm{p}<0.05$, unpaired t test; intermittent $\mathrm{n}=29$; sporadic $\mathrm{n}=60)$. ${ }^{*} \mathrm{p}<0.05 ;{ }^{* *} \mathrm{p}<0.01 ;{ }^{* * *} \mathrm{p}<0.001$. 

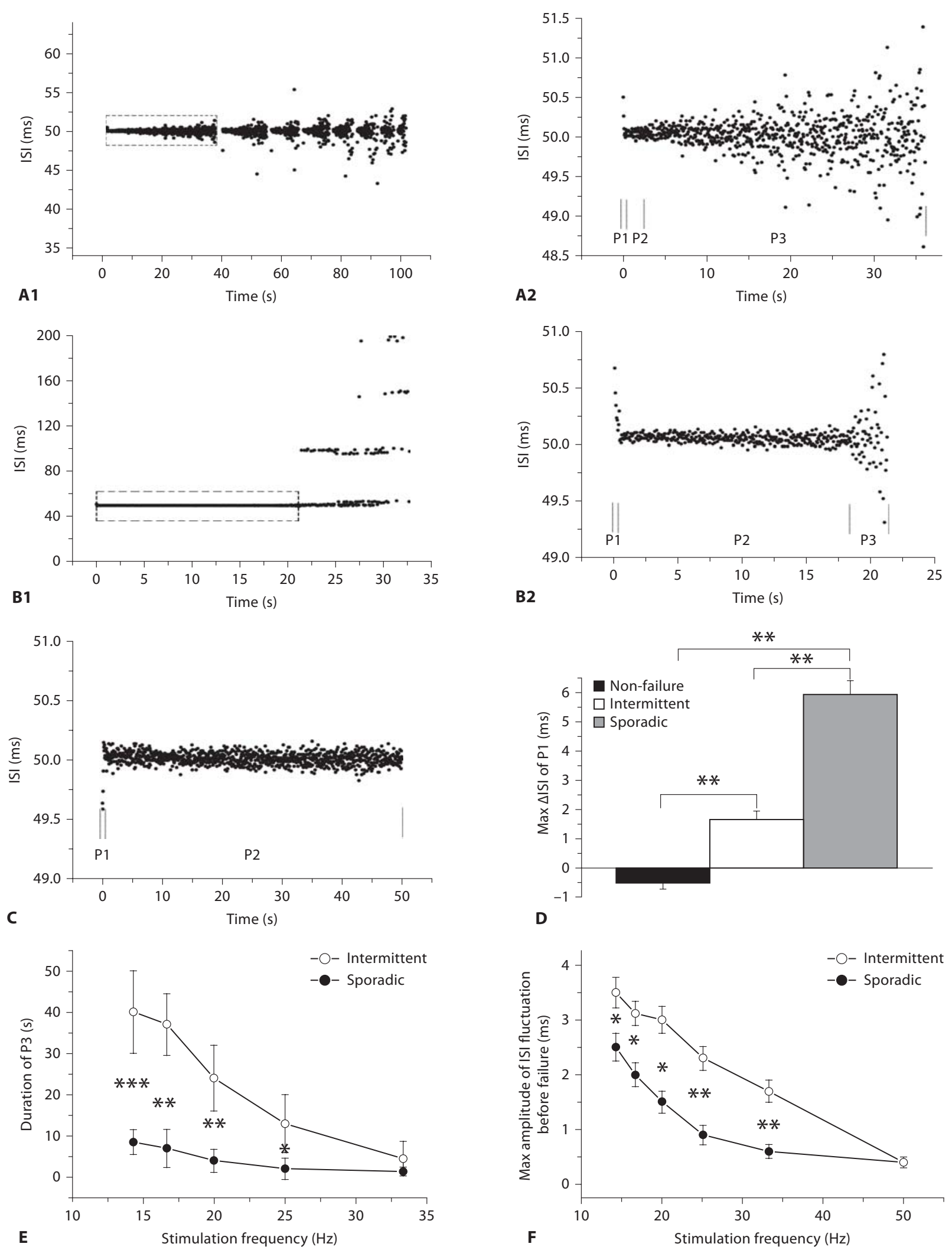

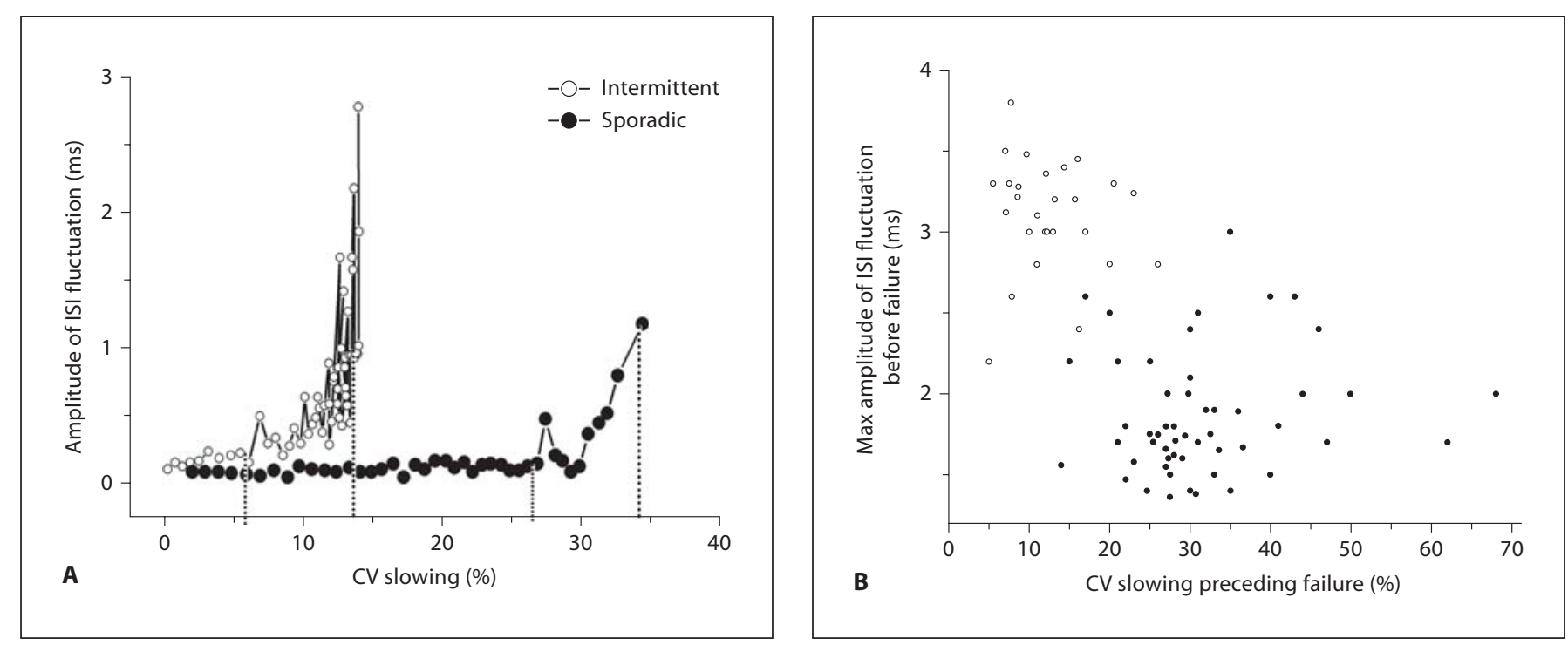

Fig. 6. Comparison of CV versus ISI fluctuation between intermittent failure and sporadic failure $C$ fibers. A Scatter plots of the amplitude of ISI fluctuation versus the degree of CV slowing before failure in two representative examples. B Relationship between CV slowing and maximal amplitude of ISI fluctuation in P3. $\bigcirc=27$ of the intermittent failure C fibers; -53 of the sporadic failure $C$ fibers. $C$ Relationship of the maximal amplitude of $\mathrm{CV}$ fluctuation before failure and the different stimulation frequencies. ${ }^{*} \mathrm{p}<0.05$, unpaired $\mathrm{t}$ test; intermittent $\mathrm{n}=27$; sporadic $\mathrm{n}=53$.

ure $\mathrm{C}$ fibers. In non-failure $\mathrm{C}$ fibers, the ISI series only exhibited phase 1 and phase 2; no phase 3 was observed (fig. 5C). In figure 5D the maximal absolute value of $\Delta \mathrm{ISI}$ (Max $\Delta$ ISI) in phase 1 of the three types of units was compared. $\Delta$ ISI of the non-failure $C$ fibers was shorter than inter-stimulus interval $(\Delta \mathrm{ISI}=-0.51 \pm 0.1 \mathrm{~ms})$, indicating 'speeding' in the firing series. In the other two groups, the amplitudes of $\Delta$ ISI were both longer than inter-stimulus interval; only the sporadic failure $\mathrm{C}$ fibers had a markedly larger value than that of the intermittent failure C fibers $(5.93 \pm 0.48$ vs. $1.65 \pm 0.28 \mathrm{~ms}, \mathrm{p}<0.01$, unpaired $t$ test). The characteristics of phase 3 also differed between the three types. The duration of phase 3 dropped as the stimulation frequency rose. The average duration

of phase 3 of the sporadic failure $\mathrm{C}$ fibers was significantly shorter than that of the intermittent failure $\mathrm{C}$ fibers ( $p<0.05$, unpaired $t$ test; fig. 5E). Finally, the maximal amplitude of ISI fluctuation of the intermittent failure $\mathrm{C}$ fibers was significantly larger than that of the sporadic failure $C$ fibers ( $p<0.05$, unpaired $t$ test). The maximal amplitude of ISI fluctuations of the two types decreased with the increase in stimulus frequency (fig. 5F).

\section{Relationship between Amplitude of ISI Fluctuation and $C V$}

In the intermittent failure and sporadic failure $\mathrm{C}$ fibers, the relationship between amplitude of the ISI fluctuation and $\mathrm{CV}$ was further studied (fig. 6). In the typical 
Fig. 7. Influences of conduction distance on conduction failure. A Original firing series recorded on the same fiber with two different propagation distances (the top one for $85 \mathrm{~mm}$ and the bottom one for 42 $\mathrm{mm}$ ) responding to repetitive stimulation at $20 \mathrm{~Hz}$. Top trace displays intermittent failure while the bottom trace shows no failure. B Another example of the original firing series recorded on the same fiber with two different propagation distances (the top one for $88 \mathrm{~mm}$ and the bottom one for $45 \mathrm{~mm}$ ) responding to repetitive stimulation at $20 \mathrm{~Hz}$. Top trace shows sporadic failure occurring at $17 \mathrm{~s}$ after stimulation. Bottom trace shows that sporadic failure occurred $27.5 \mathrm{~s}$ after stimulation.

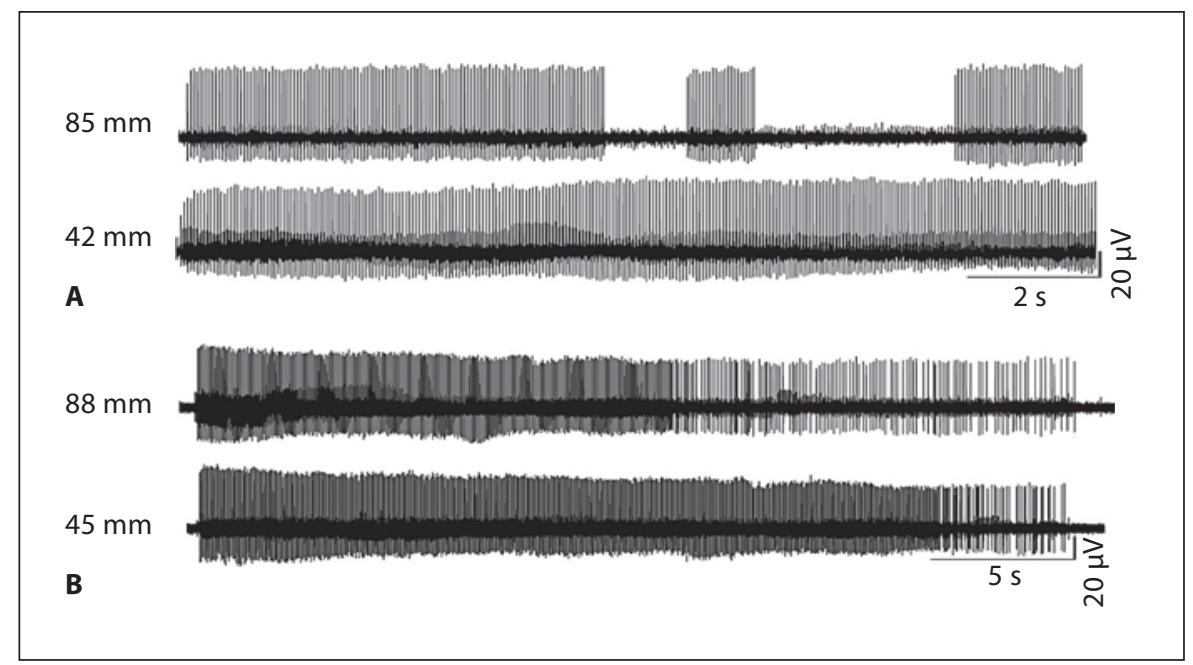

intermittent failure C fiber (fig. 6A), when CV slowing increased to more than about $6 \%$, the ISI fluctuation started to increase $(>0.2 \mathrm{~ms})$; the fluctuations continued to increase as the $\mathrm{CV}$ slowing increased. When the $\mathrm{CV}$ slowing increased to about $14 \%$, the maximal amplitude of ISI fluctuation reached nearly $3 \mathrm{~ms}$ and then failure occurred. In the typical sporadic failure $\mathrm{C}$ fiber, ISI fluctuation $(>0.2 \mathrm{~ms})$ started to appear when the CV slowing was $>27 \%$, and the failure occurred when the maximal amplitude of ISI fluctuation reached nearly $1.5 \mathrm{~ms}$ where the CV slowing increased to about $34.8 \%$. These results suggest that the amplitude of ISI fluctuation is closely related to $\mathrm{CV}$ slowing, and the conduction failure occurs when the maximal amplitude of ISI fluctuation appears. Figure 6B shows the distribution of the maximal amplitudes of ISI fluctuations along with the CV slowing preceding failure in both intermittent failure and sporadic failure $\mathrm{C}$ fibers.

We then measured the fluctuation of $\mathrm{CV}$, which is defined as the difference in $\mathrm{CV}$ of two consecutive action potentials. As shown in figure $6 \mathrm{C}$, the maximal amplitude of $\mathrm{CV}$ fluctuation before failure decreased as the stimulation frequency increased, and the maximal amplitude of $\mathrm{CV}$ fluctuation of the intermittent failure $\mathrm{C}$ fiber units was significantly greater than that of the sporadic failure $C$ fibers $(\mathrm{p}<0.05$, unpaired $t$ test), but no significant difference was observed when the stimulation frequency was higher than $50 \mathrm{~Hz}$.

\section{Influences of Conductive Distance on Conduction Failure}

After the recording fiber was identified to be the same single $\mathrm{C}$ fiber by the collision test, the effects of conduc-
Table 1. Influences of conductive distance on CV slowing and failure $(\mathrm{n}=20)$

\begin{tabular}{lllll}
\hline $\begin{array}{l}\text { Stimulus } \\
\text { site }\end{array}$ & $\begin{array}{l}\text { Conductive } \\
\text { distance } \\
\mathrm{mm}\end{array}$ & $\begin{array}{l}\mathrm{CV}_{\mathrm{i}} \\
\mathrm{m} / \mathrm{s}\end{array}$ & $\begin{array}{l}\mathrm{CV} \\
\text { slowing } \\
\%\end{array}$ & $\begin{array}{l}\text { Latency for } \\
\text { conduction } \\
\text { failure, } \mathrm{s}\end{array}$ \\
\hline $\mathrm{S}_{1}$ & $76 \pm 5$ & $1.004 \pm 0.031$ & $19.3 \pm 2.1$ & $20.1 \pm 8.0$ \\
$\mathrm{~S}_{2}$ & $44 \pm 6$ & $0.996 \pm 0.020$ & $10.7 \pm 1.6^{* *}$ & $34.5 \pm 4.0^{* *}$ \\
\hline
\end{tabular}

CV slowing measured $10 \mathrm{~s}$ after start of stimulation.

${ }^{* *} \mathrm{p}<0.01$.

tive distance on CV slowing and the pattern of failures were examined by comparing the results following stimulation at $S_{1}$ and $S_{2}$. Figure 7A shows an original record of a representative example of intermittent conduction failure. When stimulated $(20 \mathrm{~Hz}$ for $10 \mathrm{~s})$ at $\mathrm{S}_{1}$ at a distance of $85 \mathrm{~mm}$, the single $\mathrm{C}$ fiber exhibited intermittent failure, whereas when stimulated at $S_{2}$ at a distance of 42 $\mathrm{mm}$ with the same stimulation parameters, no failure was exhibited. For the sporadic failure C fiber (fig. 7B), sporadic conduction failure occurred at both conduction distances, but stimulation at $S_{2}$ evoked failure at a later time. For further analysis, 20 fibers were tested with repetitive stimuli of $20 \mathrm{~Hz}$ for $50 \mathrm{~s}$; all fibers exhibited conduction failure. The latency of the conduction failure for the shorter distance was larger than that for the longer distance (table 1). The amount of CV slowing at $10 \mathrm{~s}$ after the onset of stimulation was significantly greater for the longer distance than shorter distance (table 1). 

ure. A Firing series of an intermittent failure fiber induced by a stimulus of $20 \mathrm{~Hz}$ for tion of 4-AP at different concentrations (control, 10, 20, $40 \mu \mathrm{M}$ from top to bottom). The period of bursting firing was partially prolonged in a dose-dependent manner; note that the pattern of intermittent failure was transformed to tonic firing at $40 \mu \mathrm{M}$. B Dose-response curves for 4-AP $(n=10)$. Percentage of discharge (y axis) was valued as the number of discharges divided by the number of stimuli $\left({ }^{* * *} \mathrm{p}<\right.$ 0.001, paired t test). C Slope of CV slowing before failure after 4-AP application in $\mathbf{B}$. The slope decreased with the increase in concentration.
Fig. 8. Effect of 4-AP on conduction fail$30 \mathrm{~s}$ was recorded before and after applica-
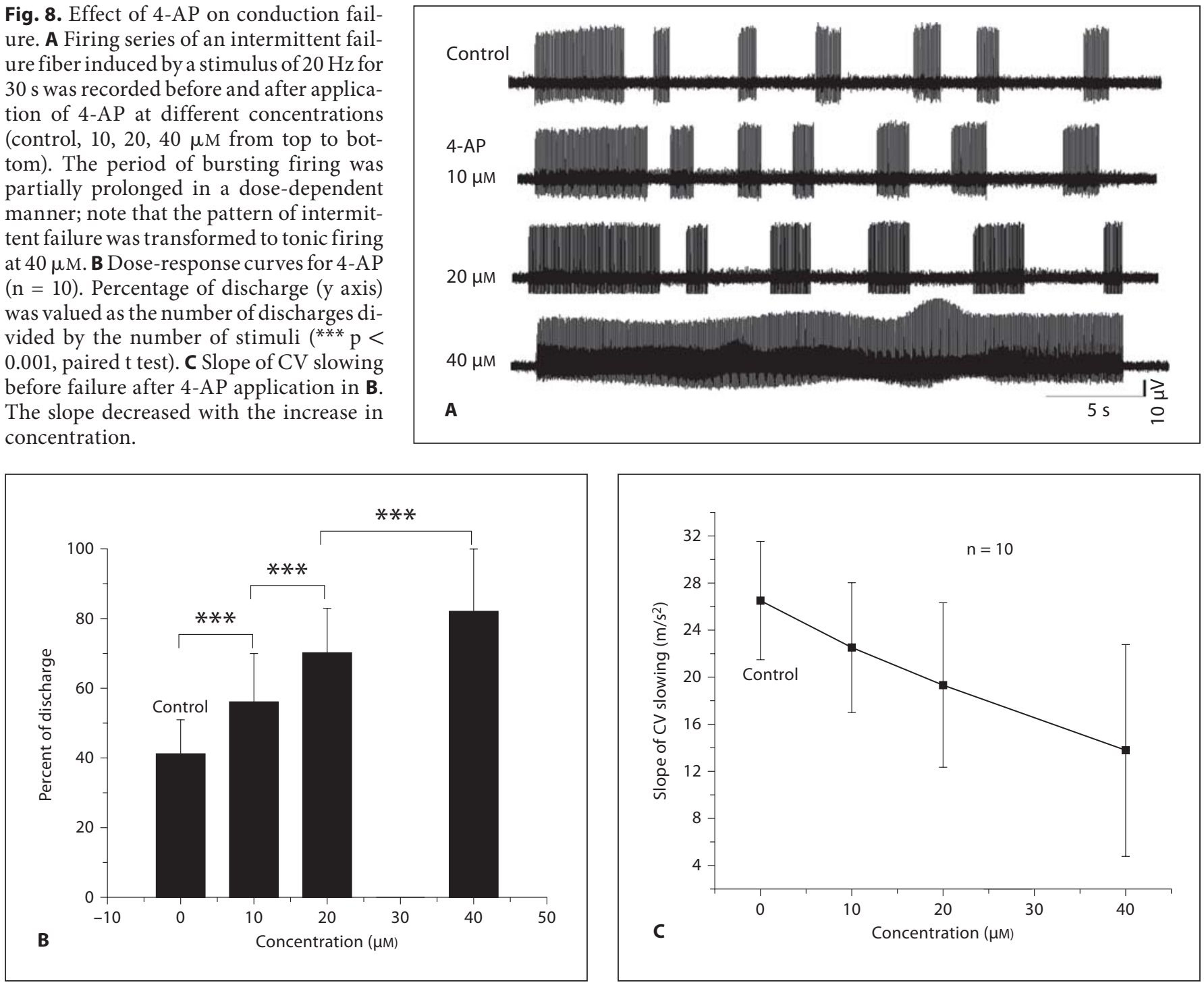

These results suggest that both the degree of CV slowing and the occurrence of failures depend on conduction distance.

\section{Conduction Failure Reduced by 4-AP}

Topical administration of 4-AP $(10-40 \mu \mathrm{M})$ in the middle pool between the stimulating and recording points produced a dose-dependent reduction in conduction failure in an intermittent failure $\mathrm{C}$ fiber. As shown in figure $8 \mathrm{~A}$, the latency for eliciting conduction failure became longer with the increase in 4-AP concentration, and the intermittent firing pattern transformed into a non-failure firing pattern after the administration of 40 $\mu \mathrm{M} 4$-AP. Figure $8 \mathrm{~B}$ shows that percentage of discharge (evaluated as the number of action potentials divided by the number of stimuli) increased in a dose-dependent manner ( $\mathrm{p}<0.001$, paired t test). The slope of CV slowing in the control state was $26.5 \pm 4.9 \mathrm{~mm} / \mathrm{s}^{2}$. When concentrations of 10,20 and $40 \mu \mathrm{M}$ of 4 -AP were applied, the slope of CV slowing was $22.5 \pm 5.5,19.3 \pm 7$ and $13.8 \pm$ $9 \mathrm{~mm} / \mathrm{s}^{2}$, respectively, indicating that the slope of CV slowing declined with the increasing concentration of 4AP (fig. 8C). In the present experiments, 40 fibers were examined for drug application, the majority of fibers (33 of 40) showed the phenomena mentioned above, while the other 7 fibers displayed no significant response. A similar effect of 4-AP on the sporadic failure $\mathrm{C}$ fibers was also observed in our experiments (data not shown). These 
Fig. 9. Effect of ZD7288 on conduction failure. A Examples of intermittent failure induced by a stimulus of $20 \mathrm{~Hz}$ for $50 \mathrm{~s}$, the traces from top to the bottom correlate to the control and the application of ZD7288 at different concentrations $(5,10,20 \mu \mathrm{M})$. The period of bursting firing was partially inhibited in a dose-dependent manner; note that the intermittent failure firing pattern almost transformed to a sporadic failure firing pattern at $20 \mu \mathrm{M}$. B Dose-response curves for ZD7288 ( $\mathrm{n}$ = $10 ;{ }^{* *} \mathrm{p}<0.01 ;{ }^{* * *} \mathrm{p}<0.001$, paired t test). C Slope of CV slowing before failure after ZD7288 application in B. The slope of CV increased with the increase in concentration.

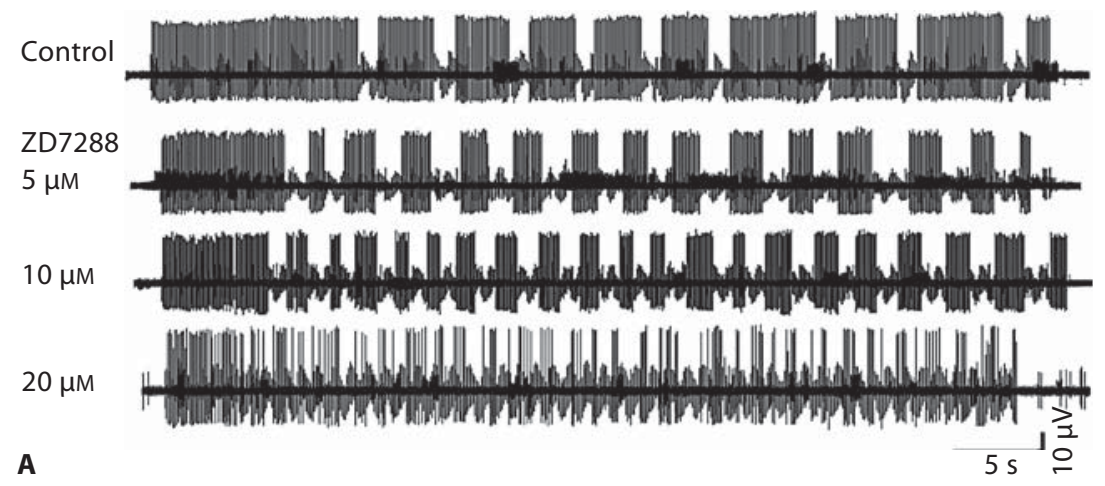

A

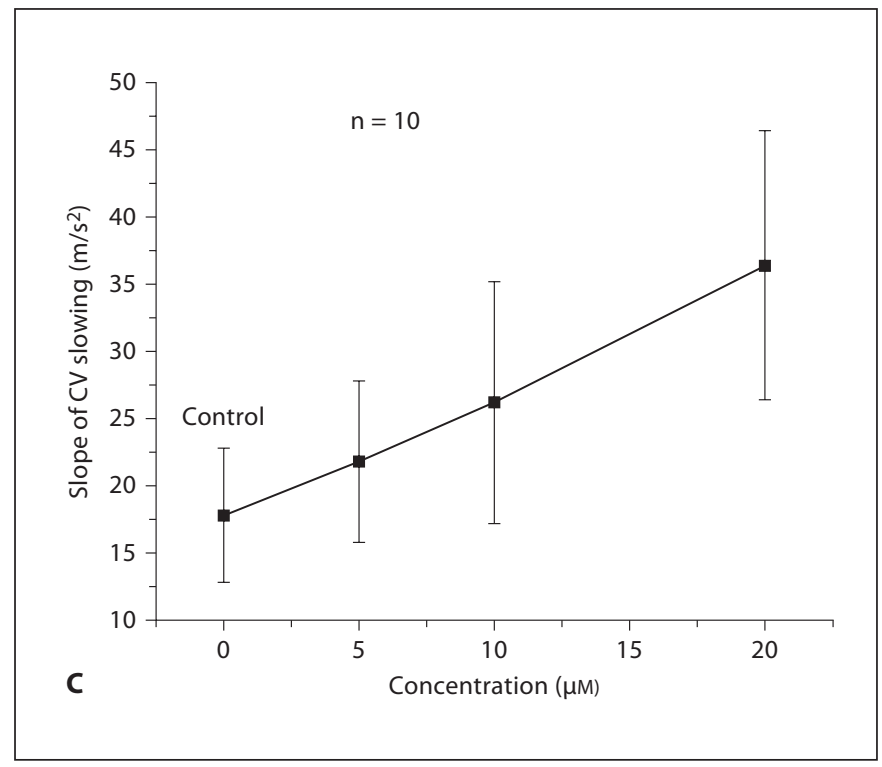

tioned phenomena, 9 of them showed no response to ZD7288, while in the other 5 fibers a negative response was observed. This indicates that ZD7288 increases the occurrence of conduction failure which was further confirmed in the majority of sporadic failure $\mathrm{C}$ fibers (data not shown).

\section{Discussion}

\section{Functional Classification of C Fibers Based on}

Conduction Properties

Investigations by others show that conduction failure occurs following moderate frequency stimulation (10-50 
$\mathrm{Hz}$ ) of the axon at the branch point or terminal arborization, indicating that conduction failure is determined by an activity-dependent effect of CV together with geometrical properties of the axon [6]. In the present study, the test frequencies of repetitive stimulation $(2-20 \mathrm{~Hz})$ inducing the occurrence of conduction failure are adequate for $\mathrm{C}$ fiber activity in their physiological range $[16,30]$. Though we measured the main axon of $\mathrm{C}$ fibers located in the trunk of the saphenous nerve which is far from both the initial segment and the axon terminals with divergence structures $[8,15]$, three types of conduction failure were observed. It has been reported that the $\mathrm{C}$ fiber in the saphenous nerve can be distinguished into nociceptive and non-nociceptive afferent fibers according to different degrees of CV slowing [30]. In the present experiment the type- 3 units with sporadic failure showed a significantly greater $\mathrm{CV}$ slowing similar to that of nociceptive afferents, while the non-failure and intermittent failure $\mathrm{C}$ fibers showed a relatively lower CV slowing similar to that of non-nociceptive afferents, though the initial CVs of the three types of $\mathrm{C}$ fibers examined in our experiment were different compared with what reported by other investigators [30]. It is interesting to note that in non-failure firing fibers, an initial speeding of $\mathrm{CV}$ was seen at the onset of the stimulus train; this is similar to the CV speeding observed in sympathetic efferent fibers [31]. Because the characteristics of failure modality and the specific $\mathrm{CV}$ change are quite distinct from each other in the different $\mathrm{C}$ fiber types, these activity-dependent conduction properties may be a useful index for a functional classification of $\mathrm{C}$ fibers.

\section{Evidence that Conduction Failure Occurs along the Course of Axon}

It is known that conduction could fail at the spike initiation point, i.e. at the location of the stimulation electrode, where the conduction failure can be prevented by increasing the current strength through the electrode [30]. In the present experiment, however, increasing the strength of stimulation current to three times the threshold could not eliminate or change the conduction failure, indicating that, in this case, the conduction failure does not occur at the spike initiation point. Several lines of evidence suggest that conduction failure occurred along the length of the axon. First, CV slowing is shown to be raised with the increase in conductive distance (table 1). We know that CV slowing is a crucial factor for processing firing patterns in C fibers $[14,19]$, which is considered an accumulative consequence of after-hyperpolarization following repetitive activity [30]. Considering that the amplitude of after-hyperpolarization is conduction distance-dependent [17], the thought that CV slowing is also conduction distance-dependent is reasonable. Second, conduction failures happened at different latencies related to the different conduction distances (fig. 7; table 1). Third, application of 4-AP or ZD7288 in the middle region (conduction area) of nerve fibers between the stimulating and recording points can significantly alter the occurrence of failure, especially if the failure can be completely abolished by 4 -AP (fig. 8A, 9A). These results strongly suggest that both a certain degree of CV slowing and adequate conductive distance are necessary for occurrence of conduction failure on the main axon of $\mathrm{C}$ fibers with uniform diameter.

\section{A Novel Predictor of Conductive Spike Failure}

In the present study, it was observed for the first time that during repetitive activity the ISI exhibits large fluctuations immediate before spike failure. Once the amplitude of ISI fluctuation becomes maximal, the conductive spike failure occurred (fig. 5A, B). Although the value of maximal amplitude of ISI fluctuation is relatively small (a few milliseconds), it can be considered an objective predictor of conductive spike failure. In other words, if there is no appearance of the maximal amplitude of ISI fluctuation, then no conductive spike failure occurs in the course of propagation in spite of the fact that the degree of CV slowing becomes much greater. It is noticeable that both the value of maximal amplitude and the time process of ISI fluctuation within intermittent and sporadic failure $\mathrm{C}$ fibers exhibit a certain distinct characteristic (fig. 5E, F), which may contribute to the identification of these two types of fibers.

In our experiment, CV slowing could be found in all three types of the fibers (fig. 3, 4), though failure only happened in those fibers in which $\mathrm{CV}$ fluctuation occurred, implying that the CV fluctuation is predictive of imminent failures. However, how CV fluctuation induces conduction failure is still not clear. A possible procedure is that during repetitive stimulus the cumulative activity-dependent effect smoothly increases CV slowing $[7,14,32,33]$. When CV slowing exceeds a certain level, the $\mathrm{CV}$ of each action potential produces fluctuations and increases gradually, finally reaching a critical value at which the failures occur (fig. 5A, B). These data force us to assume that during the period of $\mathrm{CV}$ fluctuation, the non-linear properties of after-hyperpolarization become strong. Once the latter spikes collide with a great suppressive aftereffect of the former, the latter spikes disappear. So the CV fluctuation could be considered an in- 
dex to predict whether propagation of the spike along axons fails or succeeds. However, nonlinear quantitative analysis of their interaction in the conduction course is necessary.

\section{Mechanism Underlying Modulation of Conduction Failure}

Repetitive activity in C fibers can induce their sub-excitability and reduced $\mathrm{CV}$ due to prolonged hyperpolarization $[16,20]$. However, the currents involved in modulating the firing pattern, especially conduction failure, are still not very clear. Recently, the calcium-activated $\mathrm{K}^{+}$ current and $\mathrm{I}_{\mathrm{A}}$-like $\mathrm{K}^{+}$current were shown to gate propagation in axons of the central nervous system which is constituted by non-uniform diameter structures $[3,13$, $34,35]$. In the present study we observed that, when a 4AP-sensitive $\mathrm{K}$ current $\left(\mathrm{I}_{4-\mathrm{AP}}\right)$ was blocked by low dose of 4-AP, the degree of conduction failure was reduced in a dose-dependent manner on the main axons of $\mathrm{C}$ fibers. In some extreme cases, the conduction failure disappeared when 4-AP was applied at a higher concentration (fig. 8A). In figure 8B and $\mathrm{C}$ we also see that the slope of $\mathrm{CV}$ slowing reduced with the increasing dose of 4-AP, and the ISI fluctuation, which in our opinion was considered the predicator of conduction failure, did not occur during the application of a higher dose of 4-AP. This indicates that $\mathrm{I}_{4-\mathrm{AP}}$ increases the slope of $\mathrm{CV}$ slowing through enhancing the amplitude of after-hyperpolarization and promotes the occurrence of both CV fluctuation and eventually the conduction failures.

Several studies also indicate that the after-hyperpolarization induced by repetitive stimulation could be dampened by $\mathrm{I}_{h}[11,30]$. For instance, blockade of this current can produce more failures in hippocampal Schaffer collateral axons. In the present study, it is observed on the main axons of $C$ fibers that blockade of $\mathrm{I}_{h}$ by its antagonist ZD7288 promoted conduction failure, suggesting that $\mathrm{I}_{\mathrm{h}}$, as an inward current, might compensates for the large after-hyperpolarization produced by accumulation of an activity-dependent effect in the propagation course along main axons, and then limits the occurrence of failures. These data show that a set of smaller currents operating around membrane potentials such as $\mathrm{I}_{\mathrm{h}}$ and $\mathrm{I}_{4-\mathrm{AP}}$ are pivotal for modulating the occurrence of conduction failures and the firing pattern along the main axon of $\mathrm{C}$ fibers.

\section{Functional Implications}

The function consequences of conduction failures might be of physiological importance in C fibers. For ex- ample, some C fiber nociceptors exhibit adaptation in response to a constant super-threshold stimulus [36], which is usually attributed to the transduction apparatus within the receptor terminals. However, based on results of the present experiment, this kind of adaptation phenomenon may be due, at least in part, to conduction failure along the course of axons. First, the conduction failure appears from stimulus of $\mathrm{C}$ fibers, but not receptors. Second, this kind of adaptation phenomenon depends not only on the rate and time of stimulus, but also the conduction distance (table 1; fig. 7). Finally, CV slowing that reflects the degree of activity dependence in the conduction course is an important determinant of this failure occurrence. It is possible to believe that the firing pattern might be modulated within the parent axon, so that the temporal pattern of response to natural stimuli may be altered along the course of the axon in sensory $\mathrm{C}$ fibers.

The effect that the axon of $\mathrm{C}$ fiber serves to modify the code of action potential trains arising from the free nerve ending may explain changes in the responses associated with various pathologies such as small-fiber peripheral neuropathy. For instance, erythromelalgia (a painful condition in which patients exhibit red and hot extremities) may be associated with mutations in SCN9A [37]; impulse propagation was altered in afferent $\mathrm{C}$ fibers with lower $\mathrm{CV}$ and a more pronounced activity-dependent slowing [38]. In an established model of painful diabetic neuropathy in the rat, a subset of $\mathrm{C}$ fibers demonstrated a marked hyper-responsiveness to mechanical stimuli and a greater mean CV [23]. Activation of the axonal receptor of 5-HT(3), an important inflammatory mediator, not only enhances membrane excitability but also modulates action potential trains in nociceptive $\mathrm{C}$ fibers at high impulse rates [39]. Based on these data we hypothesize that some pathological conditions, including inflammation, diabetic neuropathy and mutation in some specific genes, could perturb the adaptation properties by changing channel current balance and altering both the numbers and patterns of firing series, ultimately influencing perception. Whether this is true still needs to be explored further.

On the other hand, conduction failure has been observed experimentally in various axons at the branch point or terminal arborization as reviewed by Debanne [6]. When some spikes fail to propagate along the axon, not only does the number of spikes decrease, but the temporal patterns of spikes, in which certain neural information may be contained, also change somewhat [40]. So the conduction failures have recently received a great deal of 
attention for their important role in information processing in the peripheral and central nervous systems. In the present study the conduction failures were found in the main axon of $C$ fibers, suggesting that the function of information processing could also operate in the propagating course along $\mathrm{C}$ fibers where there are no effects of obvious geometrical factors, and our term for it is 'conduction coding'. This conduction coding of neural signal processing distinguishes it from some recognized modes of information processing which occurs at a special re- gion of the neuron or branch point of an axon, and this kind of novel mode may contribute to understanding the overall picture of neural coding.

\section{Acknowledgements}

We thank Prof. Richard A. Meyer (Johns Hopkins University, Baltimore, Md., USA) for his critical reading and modification of the manuscript. This work was supported by the National Scientific Foundation of China Key Grant (30530260).

\section{References}

1 Mackenzie PJ, Umemiya M, Murphy TH: $\mathrm{Ca}^{2+}$ imaging of CNS axons in culture indicates reliable coupling between single action potentials and distal functional release sites. Neuron 1996;16:783-795.

2 Koester J, Siegelbaum SA: Propagated signaling: the action potential; in Kandel ER, Schwartz JH, Jessell TM (eds): Principles of Neural Science, ed 4. New York, McGrawHill, 2000, p 159.

-3 Bielefeldt K, Jackson M: A calcium-activated potassium channel causes frequency-dependent action potential failures in a mammalian nerve terminal. J Neurophysiol 1993;70: 284-298.

-4 Segev I, Schneidman E: Axons as computing devices: basic insights gained from models. J Physiol (Paris) 1999;93:263-270.

5 Antic S, Wuskell JP, Loew L, Zecevic D: Functional profile of the giant metacerebral neuron of Helix aspersa: temporal and spatial dynamics of electrical activity in situ. J Physiol (Lond) 2000;527:55-69.

-6 Debanne D: Information processing in the axon. Nat Rev Neurosci 2004;5:303-316.

7 Philip ML, Gila MT, David JT, Hugh B, Peter G: Activity-dependent modulation of axonal excitability in unmyelinated peripheral rat nerve fibers by the $5-\mathrm{HT}_{3}$. J Neurophysiol 2006;96:2963-2971.

8 Grossman Y, Parnas I, Spira MF: Differential conduction block in branches of a bifurcating axon. J Physiol 1979;295:283-305.

-9 Grossman Y, Parnas I, Spira MF: Ionic mechanisms involved in differential conduction of action potentials at high frequency in a branching axon. J Physiol 1979;295:307322.

10 Tsubokawa H, Ross WN: Muscarinic modulation of spike back propagation in the apical dendrites of hippocampal CA1 pyramidal neurons. J Neurosci 1997;17:5782-5791.

11 Soleng AF, Chiu D, Raastad M: Unmyelinated axons in the rat hippocampus hyperpolarize and activate an $\mathrm{H}$ current when spike frequency exceeds 1HZ. J Physiol (Lond) 2003;552:459-470.
2 Weidner C, Schmidt R, Schmelz M, Torebjork HE, Handwerk HO: Action potential conduction in the terminal arborisation of nociceptive C-fiber afferents. J Physiol 2003; 547:931-940.

13 Debanne D, Guérineau NC, Gahwiler BH, Thompson SM: Action-potential propagation gated by an axonal IA-like K+ conductance in hippocampus. Nature 1997;389: 286-289.

14 Serra J, Campero M, Ochoa J, Bostock H: Activity-dependent slowing of conduction differentiates functional subtypes of $\mathrm{C}$ fibers innervating human skin. J Physiol 1999;515: 799-811.

15 Yau KW: Receptive fields, geometry and conduction block of sensory neurons in the central nervous system of the leech. J Physiol 1976;263:513-538.

16 Ritchie JM, Straub RW: The hyperpolarization which follows activity in mammalian non-medullated fibers. J Physiol 1957;136: 80-97.

17 Richie JM, Straub RW: The after-effects of repetitive stimulation on mammalian nonmedullated fibres. J Physiol 1956;134:698711.

18 Jansen JK, Nicholls JG: Conductance changes, an electrogenic pump and the hyperpolarization of leech neurons following impulses. J Physiol (Lond) 1973;229:635-655.

19 Weidner C, Schmelz M, Schmidt R, Hammarberg B, Orstavik K, Hilliges M, Torebjork HE, Handwerker HO: Neural signal processing: the underestimated contribution of peripheral human C-fibers. J Neurosci 2002;22:5704-5712.

20 Bostock H, Grafe P: Activity-dependent excitability changes in normal and demyelinated rat spinal root axons. J Physiol 1985;365: 229-257.

21 Chi SM, Hu SJ, Liu K, Ren W: Variability of conduction velocity in unmyelinated nerve fibers after excitation (in Chinese). J Fourth Milit Med Univ 1997;18:119-122.
22 Shim B, Ringkamp M, Lambrinos GL, Harke TV, Griffin JW, Meyer RA: Activity-dependent slowing of conduction velocity in uninjured L $4 \mathrm{C}$ fibers increases after an L 5 spinal nerve injury in the rat. Pain 2007;128:4051.

23 Chen X, Levine D: Hyper-responsivity in a subset of C-fiber nocicepters in a model of painful diabetic neuropathy in the rat. Neuroscience 2001;102:185-192.

$24 \mathrm{Hu}$ SJ, Zhu J: Sympathetic facilitation of sustained discharges of polymodal nociceptors. Pain 1989;38:85-90.

25 Collins WF, Randt CT: Midbrain evoked responses relating to peripheral unmyelinated or C fibers in cat. J Neurophysiol 1960;23: 47-53.

26 Kelly JS, Gage PW: L-Glutamate blocked of transmission at the giant synapse of the squid stellate ganglion. J Neurobiol 1969;1: 209-219.

27 Thoren P, Shepherd JT, Donald DE: Anodal block of medullated cardiopulmonary vagal afferents in cats. J Appl Physiol 1977;42:461465.

28 Paintal AS: Functional analysis of group III afferent fibers of mammalian muscle. J Physiol (Lond) 1960;152:250-270.

29 Peter ML, Adonis KM, Uwe W: Electrical activity of individual neurons in situ: extraand intracellular recording; in Windhost $\mathrm{H}$, Johansson H (eds): Modern Techniques in Neuroscience Research. Berlin, Springer, 1999, pp 144-145.

30 Gee MD, Lynn B, Cotsell B: Activity-dependent slowing of conduction velocity provides a method for identifying different functional classes of C-fiber in the rat saphenous nerve. Neuroscience 1996;73:667-675.

31 Ringkamp M, Johanek LM, Borzan J, Hartke TV, Campbell JN, Shim B, Meyer RA: Speeding of conduction distinguishes sympathetic efferents from unmyelinated afferents in the monkey. IASP 12th World Congress on Pain, Glasgow, 2008. 
32 Grafe P, Quasthoff S, Grosskreutz J, Alzheimer C: Function of the hyperpolarization-activated inward rectification in nonmyelinated peripheral rat and human axons. J Neurophysiol 1997;77:421-426.

-33 Bostock H, Campero M, Serra J, Ochoa J: Velocity recovery cycles of $\mathrm{C}$ fibers innervating human skin. J Physiol 2003;553:649-663.

>34 Kopysoval IL, Debanne D: Critical role of axonal A-type $\mathrm{K}^{+}$channels and axonal geometry in the gating of action potential propagation along CA3 pyramidal cell axons: a simulation study. J Neurosci 1998;18: 7436-7451.
35 Del Negro CA, Chandler SH: Physiological and theoretical analysis of $\mathrm{K}^{+}$currents controlling discharge in neonatal rat mesencephalic trigeminal neurons. J Neurophysiol 1997;77:537-553.

36 Treede RD, Andrew D, Greenspan JD: Pe ripheral coding of tonic mechanical cutaneous pain: comparison of nociceptor activity in rat and human psychophysics. J Neurophysiol 1999;82:2641-2648.

37 Yang Y, Wang Y, Li S, Xu Z, Li H, Ma L, Fan J, Bu D, Liu B, Fan Z, Wu G, Jin J, Ding B, Zhu B, Shen Y: Mutations in SCN9A, encoding a sodium channel alpha subunit, in patients with primary erythermalgia. J Med Genet 2004;41:171-174.
38 Orstavik K, Weidner C, Schmidt R, Schmelz M, Hilliges M, Jorum E, Handwerker $\mathrm{H}$, Torebjork E: Pathological C-fibers in patients with a chronic painful condition. Brain 2003; 126:567-578.

39 Lang PM, Moalem-Taylor G, Tracey DJ, Bostock H, Grafe P: Activity-dependent modulation of axonal excitability in unmyelinated peripheral rat nerve fibers by the 5 -HT(3) serotonin receptor. J Neurophysiol 2006;96: 2963-2971.

40 Ferster D, Spruston N: Cracking the neuronal code. Science 1995;270:756-757. 